\title{
Relationship between sexual orientation and psychotic experiences in the general population in England
}

Short title: Sexual orientation and psychotic experiences

Louis Jacob, $\mathrm{PhD}^{\mathrm{a}, \mathrm{b}^{*}}$; Lee Smith, $\mathrm{PhD}^{\mathrm{c}}$; Daragh McDermott, $\mathrm{PhD}{ }^{\mathrm{d}}$; Josep Maria Haro, MD-PhD ${ }^{\text {b; }}$ Andrew Stickley, $\mathrm{PhD}^{\mathrm{e}}$; Ai Koyanagi, MD-PhD ${ }^{\mathrm{b}, \mathrm{f}}$

a Faculty of Medicine, University of Versailles Saint-Quentin-en-Yvelines, Montigny-le-Bretonneux 78180, France

${ }^{\mathrm{b}}$ Research and development unit, Parc Sanitari Sant Joan de Déu, CIBERSAM,

Dr. Antoni Pujadas, 42, Sant Boi de Llobregat, Barcelona 08830, Spain

${ }^{\mathrm{C}}$ Cambridge Centre for Sport and Exercise Sciences, Anglia Ruskin University, Cambridge, United Kingdom

d School of Psychology and Sport Science, Anglia Ruskin University, Cambridge, United Kingdom

e Department of Preventive Intervention for Psychiatric Disorders, National Institute of Mental Health, National Center of Neurology and Psychiatry, Kodaira, Tokyo, Japan

f ICREA, Pg. Lluis Companys 23, Barcelona, Spain

\section{* Correspondence:}

Dr. Louis Jacob

Faculty of Medicine, University of Versailles Saint-Quentin-en-Yvelines

2 avenue de la Source de la Bièvre, Montigny-le-Bretonneux 78180 
France

Tel.: +33-(0)6-27-88-37-06

louis.jacob.contacts@gmail.com

Table count: 2

Figure count: 1

Number of appendixes: 3

Number of words in the main body of the article: 4672

Number of words in the abstract: 241

Number of characters in the title (with spaces): 102

Number of characters in the short title (with spaces): 44

Number of references: 55 


\section{Abstract}

Background: Non-heterosexual individuals are at high risk for a variety of factors associated with the emergence of psychotic experiences (PEs) (e.g., common mental disorders, substance use, stress). However, there is a scarcity of data on the association between sexual orientation and PEs. Therefore, the aim of this study was to examine the sexual orientation-PE relationship, and to identify potential mediators in this relationship.

Methods: This study used nationally representative cross-sectional data from the 2007 Adult Psychiatric Morbidity Survey (APMS). Sexual orientation was dichotomized into heterosexual and non-heterosexual. Past 12-month PE was assessed with the Psychosis Screening Questionnaire. Regression and mediation analyses were conducted to analyze the association between sexual orientation and PEs, and to identify potential mediators involved in this relationship.

Results: The final sample consisted of 7275 individuals aged $\geq 16$ years. The prevalence of non-heterosexual orientation and any PE was $7.1 \%$ and $5.5 \%$, respectively. After adjusting for sex, age, and ethnicity, non-heterosexual orientation was positively associated with any $\mathrm{PE}(\mathrm{OR}=1.99 ; 95 \% \mathrm{Cl}=1.34$ 2.93). The strongest mediators involved in this relationship were BPD traits (mediated percentage $=33.5 \%$ ), loneliness $(29.1 \%)$ and stressful life events $(25.4 \%)$

Conclusions: These findings suggest that there is a positive relationship between sexual orientation and PEs in the general population in England, and that underlying mechanisms may involve BPD traits, loneliness and stressful 
life events. Future studies with a longitudinal design are warranted to shed more light on how these factors are implicated in the association between sexual orientation and PEs.

Keywords: sexual orientation; psychotic experiences; mediation analysis; English nationally representative survey. 


\section{Introduction}

Psychotic experiences (PEs) are hallucinations and delusions that do not reach the clinical threshold for a psychosis diagnosis (DeVylder et al. 2017). The annual incidence and prevalence of PEs have been reported to be $2.5 \%$ and 7.2\%, respectively (Linscott \& van Os 2013). PEs are associated with an increased risk for psychotic disorders (Kaymaz et al. 2012), as well as several physical conditions (e.g., angina, asthma, arthritis) (Moreno et al. 2013), disability (Oh et al. 2018) and all-cause mortality (Sharifi et al. 2015). Therefore, identifying risk factors for PEs is a public health priority.

One potential risk factor that has been little studied to date is sexual orientation. Individuals with a non-heterosexual identity are known to be at high risk for a variety of factors that have been associated with the emergence of PEs [e.g., common mental disorders (CMDs) (Pakula \& Shoveller 2013), substance use (Hagger-Johnson et al. 2013), stress (Krueger et al. 2018)]. However, to the best of our knowledge, there is only one previous study that has investigated the association between sexual orientation and PEs (Gevonden et al. 2014). This Dutch study including more than 11200 participants found that lesbian, gay and bisexual individuals were more likely to report at least one psychotic symptom compared to heterosexuals [odds ratios $(O R)=2.30-2.56$ ], and this association was partially mediated by factors such as experiencing discrimination in the past year or living arrangement (i.e., living or not with a partner). Although the findings from this study are of interest, it has several limitations that should be acknowledged. First, the sample only included 
sexually active persons, and it may thus be difficult to extrapolate the results to the general population. Second, sexual orientation (i.e., preceding year) and PEs (i.e., lifetime) were not assessed during the concurrent period. Thus, temporality is difficult to establish. Third, although the mediation analysis included factors such as past-year discrimination and lifetime cannabis use, it failed to include important factors that might potentially play a major role in the association between sexual orientation and PEs. These factors include marital status, education, employment, income, nicotine dependence, alcohol dependence, loneliness, social support, lifetime bullying victimization, perceived stress, stressful life events, common mental disorders (CMDs), borderline personality disorder (BPD) traits, posttraumatic stress disorder (PTSD), and sleep problems.

Investigating the role of these factors is important as, for example, nonheterosexual orientation is positively associated with tobacco smoking (Lindström et al. 2014) and alcohol use (Hagger-Johnson et al. 2013) possibly via minority stress and peer norms, while cigarettes (Gage et al. 2014) and alcohol (Tien \& Anthony 1990) have strong psychoactive effects that can increase the risk for PEs. In addition, loneliness and a lack of social support are common in sexual minorities (Doyle \& Molix 2016), both of which may in turn lead to PEs via mental disorders (Smyth et al. 2015; Jaya et al. 2017). Moreover, non-heterosexual orientation is a risk factor for bullying victimization (Berlan et al. 2010), perceived stress (Krueger et al. 2018) and stressful life events (Austin et al. 2016), and these factors may increase the risk for PEs via elevated baseline activity and responsivity of the hypothalamic-pituitary- 
adrenal (HPA) axis (Beards et al. 2013; Catone et al. 2015; DeVylder et al. 2016). Sexual minorities are also known to be at a particularly high risk for CMDs (Pakula \& Shoveller 2013), BPD traits (Reuter et al. 2016) and PTSD (Roberts et al. 2010), and these associations may be explained by exposure to discrimination, social isolation and limited mental health service utilization. On the other hand, these mental health conditions are well-known risk factors for subclinical psychotic symptoms (Varghese et al. 2011; Alsawy et al. 2015; Niemantsverdriet et al. 2017). Finally, the prevalence of sleep problems is high in sexual minorities, and this may be explained by a lack of social resources, high levels of distress and unhealthy behaviors (Chen \& Shiu 2017). Sleep problems may in turn favor the occurrence of PEs via anxiety, depression and stress (Reeve et al. 2018).

Therefore, the goal of the present nationally representative study using community-based data from the 2007 Adult Psychiatric Morbidity Survey (APMS) conducted in England was to analyze the association between sexual orientation and past 12-month PEs, and to identify the potential mediators involved in this relationship. Given that approximately 1.1 million people identify themselves as lesbian, gay or bisexual in Britain (Geary et al. 2018), and that access to healthcare is often difficult for sexual minorities (McNamara \& $\mathrm{Ng}$ 2016), investigating this association using community-based data is important to obtain a better understanding of the epidemiology of PEs in this setting. 


\section{Methods}

\section{Study participants}

This study used data from 7403 people who participated in the 2007 APMS. Full details of the survey have been published elsewhere (Jenkins et al. 2009; McManus et al. 2009). Briefly, this was a nationally representative survey of the English adult population (aged $\geq 16$ years) living in private households. The National Center for Social Research and Leicester University undertook the survey fieldwork in October 2006 to December 2007 using a multistage stratified probability sampling design where the sampling frame consisted of the small user postcode address file, while the primary sampling units were postcode sectors. Participant information was obtained through face-to-face interviews where some of the questionnaire items were self-completed (with the use of a computer). Sampling weights were constructed to account for nonresponse and the probability of being selected so that the sample was representative of the English adult household population. The survey response rate was $57 \%$. Ethical permission for the study was obtained from the Royal Free Hospital and Medical School Research Ethics Committee. All participants provided informed consent before their inclusion.

\section{Measures}

\section{Sexual orientation (independent variable)}

Two items, adapted from the Kinsey scale, were used to measure sexual orientation: (a) "Which statement best describes your sexual orientation? This means sexual feelings, whether or not you have had any sexual partners." with 
answer options "entirely heterosexual", "mostly heterosexual", "bisexual", "mostly homosexual", "entirely homosexual", and "other"; and (b) "Please choose the answer below that best describes how you currently think of yourself..." with answer options "completely heterosexual", "mainly heterosexual", "bisexual", "mainly homosexual", "completely homosexual", and "other". Participants were randomly allocated to item (a) and item (b) in order to analyze the impact of question wording and format on the prevalence of nonheterosexual orientation in the sample. As in a previous APMS publication, the two items were combined, and heterosexual orientation was operationalized as replying "entirely heterosexual" to the first item or "completely heterosexual" to the second item (Chakraborty et al. 2011). All other individuals were considered to be non-heterosexual.

Psychotic experiences (dependent variable)

The Psychosis Screening Questionnaire (PSQ), which consists of sections on hypomania/mania, thought control, paranoia, strange experiences, and auditory hallucinations, was used to assess PEs in the past 12 months. As in a previous publication using the same dataset, the strictest criteria were used to define the presence or absence of psychotic symptoms in an attempt to capture truly anomalous experiences (Jacob et al. 2018b). The questions used in the PSQ can be found in Appendix 1. Any PE referred to the endorsement of at least one of the five types of PE. 


\section{Mediating variables}

These variables were selected based on previous literature (Tien \& Anthony 1990; Berlan et al. 2010; Roberts et al. 2010; Varghese et al. 2011; Beards et al. 2013; Hagger-Johnson et al. 2013; Pakula \& Shoveller 2013; Bauermeister et al. 2014; Gage et al. 2014; Gevonden et al. 2014; Lindström et al. 2014; Alsawy et al. 2015; Catone et al. 2015; McGrath et al. 2015; Mollborn \& Everett 2015; Smyth et al. 2015; Austin et al. 2016; DeVylder et al. 2016; Doyle \& Molix 2016; Reuter et al. 2016; Chen \& Shiu 2017; Jaya et al. 2017; Lunn et al. 2017; Niemantsverdriet et al. 2017; Charlton et al. 2018; Davies et al. 2018; Krueger et al. 2018; Reeve et al. 2018). Specifically, factors that have been reported to be associated with sexual orientation, and can precede or cause PEs were selected. These factors were marital status, qualification, employment, income, nicotine dependence, alcohol dependence, cannabis use, loneliness, social support, bullying victimization, perceived stress, number of stressful life events, discrimination due to sexual orientation, CMDs, BPD traits, PTSD, and sleep problems. Loneliness and lack of social support were both considered as separate mediators as they are distinct concepts which do not necessarily correlate. Specifically, loneliness refers to a subjective feeling of being alone, whereas lack of social support refers to objective social exclusion (Tomaka et al. 2006). Perceived stress and stressful life events were also included as separate mediators as perceived stress refers to a global and dynamic multidimensional subjective concept that is influenced by numerous factors (e.g., sociodemographics, personality, lifestyle factors), whereas stressful life events refer to specific events that are known be objectively associated with stress (Feizi et al. 2012). 
Sociodemographic factors. These included marital status (married/cohabiting or single/widowed/divorced/separated), qualification (having a qualification i.e., degree, non-degree, A-level, GCSE, other: yes or no), employment status, and income (highest $\geq £ 29826$, middle $£ 14057-<£ 29826$ or lowest $<£ 14057$; equivalized income tertiles).

Nicotine dependence. Nicotine dependence was assessed using the Fagerström test, a six-item questionnaire (Chabrol et al. 2005). The score of the test ranges from 0 to 10 , and a score of $\geq 6$ indicates dependence to nicotine. A dichotomized variable was created (score $\geq 6$ or else).

Alcohol dependence. Excessive alcohol consumption was screened using the Alcohol Use Disorders Identification Test (AUDIT). Alcohol dependence was assessed with the Severity of Alcohol Dependence Questionnaire (SADQ-C) in participants with an AUDIT score of 10 or above. Scores of four or above indicated alcohol dependence in the past six months (Jacob et al. 2019).

Cannabis use. Cannabis use referred to answering affirmatively to the question "In the last 12 months, have you taken cannabis?" Data on the frequency of lifetime cannabis use were also available and this variable was dichotomized as $<10$ or $\geq 10$ times.

Loneliness. Loneliness was assessed with an item from the Social Functioning Questionnaire (SFQ). Respondents were asked to assess to what extent they had felt "lonely and isolated from other people" in the past 2 weeks with response options, "very much", "sometimes", "not often", and "not at all". In the analyses that follow, these response options were dichotomized with those who responded "sometimes" and "very much" being categorized as lonely (Jacob et al. 2019). 
Social support. This was assessed with a 7-item measure. Using answer options "not true" (score=0), "partly true" (score=1), and "certainly true" (score=2), participants responded to statements which inquired if family and friends did things to make them happy, made them feel loved, could be relied on no matter what, would see that they were taken care of no matter what, accepted them just the way they are, made them feel an important part of their lives, and gave them support and encouragement. Responses were added to create a scale score that could range from 0 to 14 . The internal consistency of the scale was good: Cronbach's $\alpha=0.89$.

Bullying victimization. Those who claimed to have been bullied at any time in life were considered to have experienced bullying (Jacob et al. 2018a).

Perceived stress. Participants were asked if their tasks at home and at work were stressful. Answers ranged from 0 "not at all" to 3 "most of the time". Stress was then dichotomized into "not at all" versus "occasionally", "usually", and "most of the time" (Jacob et al. 2019).

Stressful life events. Eighteen items were used to assess different stressful life events (e.g., serious illness, death of an immediate family member, major financial crises) (Jacob et al. 2019). The total number of stressful life events was further calculated for each participant and ranged from 0 to 18 .

Discrimination due to sexual orientation. Participants were asked if they had been unfairly treated in the past 12 months because of their sexual orientation. Common mental disorders. These were assessed using the Clinical Interview Schedule Revised (CIS-R) and referred to depressive episode and/or anxiety disorders (i.e., generalized anxiety disorder, panic disorder, phobia, obsessivecompulsive disorder) in the past week (Jacob et al. 2019). 
Borderline personality disorder traits. The presence of the nine diagnostic criteria for BPD was assessed by the Structured Clinical Interview for DSM-IV Axis II disorders. The scores from each of the criteria (yes=1 and no=0) were added to create a scale ranging from $0-9$ (Cronbach's $\alpha=0.74)$. Following the lead of a previous publication using the same dataset (Kelleher et al. 2017), the cutoff to represent high BPD traits was based on a figure that corresponds to a prevalence which is approximately 10 times higher than that of BPD $(0.4 \%$ in this dataset). Specifically, a score of $\geq 6$ was used as the cutoff to construct the dichotomous variable subsequently used in the analyses, with a score of $\geq 6$ coded as 1 and a score of $<6$ coded as 0 . Owing to the fact that there were only 16 individuals with BPD in our dataset, we were unable to conduct meaningful analyses with BPD. Thus, rather, we focused on high BPD traits.

Posttraumatic stress disorder. The Trauma Screening Questionnaire (TSQ) was used to examine PTSD symptoms. "Reliving" of the traumatic event was assessed with five items, while experiencing "arousal" subsequent to the trauma was assessed with five other items. Each item with an affirmative answer was given one point, and a total score of $\geq 6$ points out of the possible 10 indicated a positive screen for PTSD, or probable PTSD (Alsawy et al. 2015). Sleep problems. Two questions were used to assess sleep problems: "In the past month, have you been having problems with trying to get to sleep or with getting back to sleep if you woke up or were woken up?" (sleeping less than usual) and "Has sleeping more than you usually been a problem for you in the past month?" (sleeping more than usual). Participants were considered as having sleep problems if they reported sleeping less or more than usual. 


\section{Control variables}

The present study controlled for sex, age and ethnicity (British White: yes or no).

\section{Statistical analyses}

Individuals with definitive or probable psychosis were omitted from the analysis as the focus of the study was on PEs not reaching the clinical threshold for a psychosis diagnosis (definition provided in Appendix 2). Differences in the sample characteristics by sexual orientation (heterosexual versus nonheterosexual) were tested with Chi-squared tests for categorical variables and Student's t-tests for continuous variables.

We conducted multivariable logistic regression analyses to assess the association between sexual orientation (independent variable) and the individual types of PE and any PE (dependent variables). Sensitivity analysis by the two groups that were administered different questions on sexual orientation was subsequently performed. We further conducted mediation analysis to quantify the degree to which the association between sexual orientation and PEs may be explained by factors which can theoretically be mediators in this association. The khb (Karlson Holm Breen) command in Stata was used for this analysis (Breen et al. 2013). This method can be applied in logistic regression models and decomposes the total effect (i.e., unadjusted for the mediator) of a variable into direct (i.e., the effect of sexual orientation on any PE adjusted for the mediator) and indirect effects (i.e., the mediational effect). Using this method, the percentage of the main association explained by 
the mediator can also be calculated (mediated percentage). Each of the 17 mediating factors was included individually in the model.

The regression analyses including the mediation analysis were adjusted for sex, age and ethnicity. Furthermore, since previous research has found that the association between sexual orientation and mental health disorders differs by sex (Bolton \& Sareen 2011), an interaction analysis was conducted by including the product term of sexual orientation $x$ sex in the models. All variables used in the analyses were categorical variables with the exception of age, social support and the number of stressful life events. The sample weighting and the complex study design (i.e., strata and primary sampling units) were taken into account in all analyses with the use of the svy command in Stata, which relies on the Taylor linearization method. Under $2.0 \%$ of the values were missing for all the variables used in our study with the exception of income $(20.0 \%)$. Complete case analysis was done. The level of statistical significance was set at $p<0.05$. All analyses were performed with Stata version 13.1 (Stata Corp LP, College Station, Texas, USA).

\section{Results}

There were 7403 people aged $\geq 16$ years who participated in the 2007 APMS. We excluded 40 people who had probable psychosis from the study. Of the remaining 7363 individuals, a further 88 were excluded due to lack of information on definitive/probable psychosis and/or sexual orientation. The prevalence of non-heterosexual orientation and any PE was $7.1 \%$ and $5.5 \%$, respectively. The sample characteristics are displayed in Table 1. Ethnicity other than British White, single/widowed/divorced/separated, alcohol 
dependence, cannabis use, loneliness, bullying victimization, perceived stress, discrimination due to sexual orientation, CMDs, BPD traits, PTSD, and sleep problems were more common, and age and social support lower, while the number of stressful life events higher in non-heterosexual than in heterosexual individuals. The prevalence of any PE was $10.6 \%$ and $5.1 \%$ in nonheterosexual and heterosexual participants, respectively. After adjusting for sociodemographic factors (i.e., sex, age, ethnicity), non-heterosexual orientation was positively associated with any PE [odds ratio $(O R)=1.99 ; 95 \%$ confidence interval $(\mathrm{Cl})$ : 1.34-2.93], hypomania/mania $(\mathrm{OR}=3.66 ; 95 \% \mathrm{Cl}$ : $1.47-$ 9.13), paranoia $(\mathrm{OR}=2.06 ; 95 \% \mathrm{Cl}$ : 1.17-3.63), and strange experiences $(\mathrm{OR}=2.19 ; 95 \% \mathrm{Cl}: 1.38-3.46$; Figure 1). Interaction analysis further revealed that sex was not a significant effect modifier in the sexual orientation-PE relationship (data not shown). The results of the sensitivity analysis by the two groups that were administered different questions on sexual orientation were similar, and this suggests that the phrasing of the question had little impact on the results. Finally, the results of the mediation analyses are shown in Table 2. The association between sexual orientation and any PE was significantly mediated by BPD traits (mediated percentage $=33.5 \%$ ), loneliness $(29.1 \%)$, stressful life events $(25.4 \%)$, sleep problems (19.1\%), CMDs (18.1\%), bullying victimization (15.9\%), marital status (13.0\%), social support $(10.5 \%)$, perceived stress $(8.9 \%)$, cannabis use $(8.4 \%)$, PTSD $(8.3 \%)$, and alcohol dependence (6.4\%). The mediated percentage for cannabis use was $5.9 \%$ when frequency (i.e., $\geq$ or $<10$ times in life) was taken into account (data shown only in text). The level of pair-wise correlation between the mediators is shown in Appendix 3. A high level of correlation was not observed for any of the pairs. 


\section{Discussion}

\section{Main findings}

To the best of our knowledge, this is one of the first studies to examine the association between sexual orientation and PEs, while it is the first to investigate the potential mediating role played by a wide range of factors in this association. In this nationally representative study of English adults, the prevalence of any PE was around $11 \%$ in the non-heterosexual group and $5 \%$ in the heterosexual group. The regression analysis adjusted for sociodemographic factors (i.e., sex, age, ethnicity) further revealed that nonheterosexual orientation was associated with a 2.0-fold increase in the risk for any PE compared to heterosexual orientation. We also found that the association of sexual orientation with hypomania/mania, paranoia and strange experiences was particularly strong and this suggests that sexual orientation may not impact all types of PEs similarly. Finally, BPD traits, loneliness and stressful life events explained around $25 \%$ to $34 \%$ of the sexual orientation-any PE relationship. Substance use had very little influence in the association.

\section{Interpretation of the findings}

The fact that non-heterosexual individuals were at higher risk for PE in our study is in line with the earlier Dutch study which found that non-heterosexual orientation was associated with a 2.30-2.56 times higher odds for PE (Gevonden et al. 2014). The results also accord with those of previous studies that have investigated the association between sexual orientation and more severe forms of psychosis. For example, a nationally representative study using 
data from around 34700 US participants showed that sexual minorities (e.g., gay, bisexual) were at an increased risk for psychosis, with ORs ranging from 1.99 to 2.70 (Bolton \& Sareen 2011). Another UK study found in more than 7400 adults that there was more than a three-fold increase in the risk for probable psychosis in non-heterosexual individuals compared to heterosexual individuals (Chakraborty et al. 2011).

In terms of the mediators, we found that borderline personality traits, loneliness and stressful life events explained more than $25 \%$ of the association between sexual orientation and PE, while other factors such as sleep disorders, CMDs, bullying victimization, marital status, and social support explained $10-20 \%$ of the association. In contrast, the most important mediator identified in the Dutch study was past-year discrimination due to sexual orientation (34\%) (Gevonden et al. 2014). Although we used a similar variable, discrimination due to sexual orientation was not a significant mediator in our study. This discrepancy in the findings highlights the fact that psychosocial factors involved in the sexual orientation-PE relationship may be population or context specific. Regarding substance use, the results of the two studies concur and show that it only plays a minor mediating role.

In our study, stressful life events explained around $25 \%$ of the sexual orientation-PE relationship. A longitudinal study conducted in the US and including young adults followed for more than a decade showed that stressful life events (e.g., a life-threatening event, death of a loved one, divorce) were more frequent in bisexual or lesbian and in mostly heterosexual women than in 
their completely heterosexual counterparts (Austin et al. 2016). On the other hand, a meta-analysis of 16 studies further reported that stressful life events increased the risk for psychotic disorder or subclinical psychosis $(\mathrm{OR}=3.19)$ (Beards et al. 2013). The association between stressful life events and PEs likely involves several mechanisms such as negative distortions of perception of the external world and dysregulations of the HPA axis (Beards et al. 2013). Bullying victimization may also be implicated in the sexual orientation-PE association in a similar way. Although some stressful life events and bullying victimization could have occurred for a variety of reasons during childhood and adolescent developmental stages, youths who will later identify as being nonheterosexual may display certain levels of gender non-conformity, and this could make them more susceptible to parental maltreatment at home or peer bullying at school during this formative period (Gevonden et al. 2014).

Loneliness also explained an important proportion of the association between sexual orientation and PEs. A previous study showed that sexual minorities (i.e., mostly heterosexual, bisexual, mostly gay/lesbian, gay/lesbian) are more likely to be lonely possibly due to marginalization (Doyle \& Molix 2016). In turn, loneliness may lead to PE via depression and other mental disorders (Jaya et al. 2017). Interestingly, despite this finding on loneliness, social support explained the sexual orientation-PE association to a much lesser extent in our study. This may mean that the self-perception of social relationships is more important than actual social ties. 
Next, a variety of psychopathology including BPD, CMDs and PTSD has been reported to be more common in non-heterosexual individuals, and this may be due to factors such as chronic environmental invalidation (e.g., negation of emotions, dismissal of cognitive experiences) and disruptions in identity formation (Reuter et al. 2016). On the other hand, PEs are known to be highly prevalent among those with BPD and other psychiatric conditions (Niemantsverdriet et al. 2017). Moreover, an important proportion of nonheterosexual individuals are affected by sleep disorders (Chen \& Shiu 2017), and sleep problems have been reported to induce PEs (Koyanagi \& Stickley 2015). Furthermore, perceived stress is highly frequent in sexual minorities (Krueger et al. 2018), and the association between perceived stress and PEs may involve chronic hyperactivity of the HPA axis (DeVylder et al. 2016). However, it is also important to note that the mediators identified in our study may be operating at multiple levels of the causal pathway. For example, nonheterosexual orientation may lead to increased levels of perceived stress (Krueger et al. 2018), while this in turn, may increase risk for sleep problems (Charles et al. 2011) and a variety of mental disorders (Bergdahl \& Bergdahl 2002), which could lead to the emergence of PEs (Varghese et al. 2011; Reeve et al. 2018). Finally, it is possible that other factors which were not measured in our study may be implicated in the sexual orientation-PE relationship, and these may include factors such as cortisol levels (Collip et al. 2011) and sexually transmitted diseases (Alciati et al. 2001; Fenton et al. 2005). 
Clinical implications and directions for future research

The results of our study showed that PEs in non-heterosexual individuals are likely to be explained, at least in part, by psychosocial factors (e.g., loneliness, stressful life events, bullying victimization) and mental health conditions (e.g., BPD traits, CMDs, PTSD). Clinicians should be aware that these conditions are more common among non-heterosexuals and that these may be underlying factors for PEs. Taken together, our findings highlight the importance of the social context in the sexual orientation-PE relationship. These findings also underline the need for new programs aiming at the improvement of the health, safety and well-being of sexual minorities. In addition, lack of acceptance of non-heterosexual individuals may have considerable effects on their health and well-being, and this should be the focus of collective efforts in the future. Finally, further studies that investigate the underlying mechanisms that lead to stronger associations between sexual orientation and certain types of PE are warranted.

\section{Limitations}

First, in order to achieve a sample of individuals without clinical psychosis, we used a conservative approach of excluding not only individuals with a definitive psychosis diagnosis but also people with probable psychosis. However, it is possible that some individuals with probable psychosis did not have clinical psychosis, and thus, some individuals without clinical psychosis could have been excluded. Second, the design of this study was cross-sectional, and it was thus not possible to determine causality or temporality in the sexual orientationPE relationship. Relatedly, mediation and confounding have been found to be identical statistically and distinguished only on conceptual grounds in the 
context of ordinary least squares regression (MacKinnon et al. 2000). While many of the mediating variables assessed in this study can be conceptualized as mediators, it is not possible to determine whether the attenuation in the ORs after the inclusion of the mediating variable is due to mediation or confounding in our cross-sectional study. Nonetheless, given that the influential factors in the association between sexual orientation and PE are largely unknown, we believe that our study provides an important platform for future longitudinal studies to provide more concrete evidence for the establishment of causality.

\section{Conclusion}

Our findings suggest that there is a positive relationship between nonheterosexual orientation and PEs in the general population in England, and that underlying mechanisms may involve other mental health conditions as well as psychosocial factors. Further studies with a longitudinal design are warranted to understand in more detail, how these factors are implicated in the association between sexual orientation and PEs.

\section{Acknowledgements}

We would like to thank the National Center for Social Research and the University of Leicester who were the Principal Investigators of this survey. In addition, we would also like to thank the UK Data Archive, the National Center for Social Research, and other relevant bodies for making these data publicly available. They bear no responsibility for this analysis or interpretation of this publicly available dataset. 


\section{Availability of Data and Materials}

The dataset on which the present study was based is publicly available to all interested researchers but they must make a formal request to the UK data service data repository (https://www.ukdataservice.ac.uk/) where the dataset is stored.

\section{Conflict of Interest}

None.

\section{Financial Support}

This research received no specific grant from any funding agency, commercial or not-for-profit sectors.

\section{Contributors}

Louis Jacob and Ai Koyanagi designed the study, managed the literature search, undertook the statistical analysis, and wrote the first draft of the manuscript. Lee Smith, Daragh McDermott, Josep Maria Haro, and Andrew Stickley contributed to the design of the study and the intellectual content. All authors contributed to and have approved the final manuscript. 


\section{References}

Alciati A, Fusi A, D’Arminio Monforte A, Coen M, Ferri A, Mellado C (2001). New-onset delusions and hallucinations in patients infected with HIV. Journal of psychiatry \& neuroscience: JPN 26, 229-234.

Alsawy S, Wood L, Taylor PJ, Morrison AP (2015). Psychotic experiences and PTSD: exploring associations in a population survey. Psychological Medicine 45, 2849-2859.

Austin SB, Rosario M, McLaughlin KA, Roberts AL, Gordon AR, Sarda V, Missmer S, Anatale-Tardiff L, Scherer EA (2016). Sexual orientation and diurnal cortisol patterns in a cohort of U.S. young adults. Psychoneuroendocrinology 69, 197-208.

Bauermeister JA, Meanley S, Hickok A, Pingel E, VanHemert W, Loveluck J (2014). Sexuality-related work discrimination and its association with the health of sexual minority emerging and young adult men in the Detroit Metro Area. Sexuality research \& social policy: journal of NSRC : SR \& SP 11, 1-10. Beards S, Gayer-Anderson C, Borges S, Dewey ME, Fisher HL, Morgan C (2013). Life Events and Psychosis: A Review and Meta-analysis. Schizophrenia Bulletin 39, 740-747.

Bergdahl J, Bergdahl M (2002). Perceived stress in adults: Prevalence and association of depression, anxiety and medication in a Swedish population. Stress and Health: Journal of the International Society for the Investigation of Stress 18, 235-241.

Berlan ED, Corliss HL, Field AE, Goodman E, Austin SB (2010). Sexual orientation and bullying among adolescents in the growing up today study. The 
Journal of Adolescent Health: Official Publication of the Society for Adolescent Medicine 46, 366-371.

Bolton S-L, Sareen J (2011). Sexual orientation and its relation to mental disorders and suicide attempts: findings from a nationally representative sample. Canadian Journal of Psychiatry. Revue Canadienne De Psychiatrie 56, 35-43.

Breen R, Karlson KB, Holm A (2013). Total, Direct, and Indirect Effects in Logit and Probit Models. Sociological Methods \& Research 42, 164-191.

Catone G, Marwaha S, Kuipers E, Lennox B, Freeman D, Bebbington P, Broome M (2015). Bullying victimisation and risk of psychotic phenomena: analyses of British national survey data. The Lancet Psychiatry 2, 618-624.

Chabrol H, Niezborala M, Chastan E, de Leon J (2005). Comparison of the Heavy Smoking Index and of the Fagerstrom Test for Nicotine Dependence in a sample of 749 cigarette smokers. Addictive Behaviors 30, 1474-1477.

Chakraborty A, McManus S, Brugha TS, Bebbington P, King M (2011). Mental health of the non-heterosexual population of England. The British Journal of Psychiatry 198, 143-148.

Charles LE, Slaven JE, Mnatsakanova A, Ma C, Violanti JM, Fekedulegn D, Andrew ME, Vila BJ, Burchfiel CM (2011). Association of Perceived Stress with Sleep Duration and Sleep Quality in Police Officers. International journal of emergency mental health 13, 229-241.

Charlton BM, Gordon AR, Reisner SL, Sarda V, Samnaliev M, Austin SB (2018). Sexual orientation-related disparities in employment, health insurance, healthcare access and health-related quality of life: a cohort study of US male and female adolescents and young adults. BMJ Open 8 
Chen J-H, Shiu C-S (2017). Sexual Orientation and Sleep in the U.S.: A National Profile. American Journal of Preventive Medicine 52, 433-442.

Collip D, Nicolson NA, Lardinois M, Lataster T, van Os J, Myin-Germeys I, G.R.O.U.P (2011). Daily cortisol, stress reactivity and psychotic experiences in individuals at above average genetic risk for psychosis. Psychological Medicine 41, 2305-2315.

Davies J, Sullivan S, Zammit S (2018). Adverse life outcomes associated with adolescent psychotic experiences and depressive symptoms. Social Psychiatry and Psychiatric Epidemiology 53, 497-507.

DeVylder JE, Cogburn C, Oh HY, Anglin D, Smith ME, Sharpe T, Jun H-J, Schiffman J, Lukens E, Link B (2017). Psychotic Experiences in the Context of Police Victimization: Data From the Survey of Police-Public Encounters. Schizophrenia Bulletin 43, 993-1001.

DeVylder JE, Koyanagi A, Unick J, Oh H, Nam B, Stickley A (2016). Stress Sensitivity and Psychotic Experiences in 39 Low- and Middle-Income Countries. Schizophrenia Bulletin 42, 1353-1362.

Doyle DM, Molix L (2016). Disparities in Social Health by Sexual Orientation and the Etiologic Role of Self-Reported Discrimination. Archives of Sexual Behavior 45, 1317-1327.

Feizi A, Aliyari R, Roohafza H (2012). Association of Perceived Stress with Stressful Life Events, Lifestyle and Sociodemographic Factors: A Large-Scale Community-Based Study Using Logistic Quantile Regression. Computational and Mathematical Methods in Medicine 2012

Fenton KA, Mercer CH, Johnson AM, Byron CL, McManus S, Erens B, Copas AJ, Nanchahal K, Macdowall W, Wellings K (2005). Reported 
Sexually Transmitted Disease Clinic Attendance and Sexually Transmitted Infections in Britain: Prevalence, Risk Factors, and Proportionate Population Burden. The Journal of Infectious Diseases 191, S127-S138.

Gage SH, Hickman M, Heron J, Munafò MR, Lewis G, Macleod J, Zammit S (2014). Associations of cannabis and cigarette use with psychotic experiences at age 18: findings from the Avon Longitudinal Study of Parents and Children. Psychological Medicine 44, 3435-3444.

Geary RS, Tanton C, Erens B, Clifton S, Prah P, Wellings K, Mitchell KR, Datta J, Gravningen K, Fuller E, Johnson AM, Sonnenberg P, Mercer CH (2018). Sexual identity, attraction and behaviour in Britain: The implications of using different dimensions of sexual orientation to estimate the size of sexual minority populations and inform public health interventions. PLoS ONE 13

Gevonden MJ, Selten JP, Myin-Germeys I, Graaf R de, Have M ten, Dorsselaer S van, Os J van, Veling W (2014). Sexual minority status and psychotic symptoms: findings from the Netherlands Mental Health Survey and Incidence Studies (NEMESIS). Psychological Medicine 44, 421-433.

Hagger-Johnson G, Taibjee R, Semlyen J, Fitchie I, Fish J, Meads C, Varney J (2013). Sexual orientation identity in relation to smoking history and alcohol use at age 18/19: cross-sectional associations from the Longitudinal Study of Young People in England (LSYPE). BMJ Open 3, e002810.

Jacob L, Haro JM, Koyanagi A (2018a). Association between intelligence quotient and violence perpetration in the English general population. Psychological Medicine, 1-8.

Jacob L, Haro JM, Koyanagi A (2018b). The association between problem gambling and psychotic experiences: Findings from the Adult Psychiatric 
Morbidity Survey 2007. Schizophrenia Research 201, 79-84.

Jacob L, Haro JM, Koyanagi A (2019). The association of religiosity with suicidal ideation and suicide attempts in the United Kingdom. Acta Psychiatrica Scandinavica 139, 164-173.

Jaya ES, Hillmann TE, Reininger KM, Gollwitzer A, Lincoln TM (2017). Loneliness and Psychotic Symptoms: The Mediating Role of Depression. Cognitive Therapy and Research 41, 106-116.

Jenkins R, Meltzer H, Bebbington P, Brugha T, Farrell M, McManus S, Singleton N (2009). The British Mental Health Survey Programme: achievements and latest findings. Social Psychiatry and Psychiatric Epidemiology 44, 899-904.

Kaymaz N, Drukker M, Lieb R, Wittchen H-U, Werbeloff N, Weiser M, Lataster T, van Os J (2012). Do subthreshold psychotic experiences predict clinical outcomes in unselected non-help-seeking population-based samples? A systematic review and meta-analysis, enriched with new results. Psychological Medicine 42, 2239-2253.

Kelleher I, Ramsay H, DeVylder J (2017). Psychotic experiences and suicide attempt risk in common mental disorders and borderline personality disorder. Acta Psychiatrica Scandinavica 135, 212-218.

Koyanagi A, Stickley A (2015). The Association between Sleep Problems and Psychotic Symptoms in the General Population: A Global Perspective. Sleep $38,1875-1885$.

Krueger EA, Meyer IH, Upchurch DM (2018). Sexual Orientation Group Differences in Perceived Stress and Depressive Symptoms Among Young Adults in the United States. LGBT Health 5, 242-249. 
Lindström M, Axelsson J, Modén B, Rosvall M (2014). Sexual orientation, social capital and daily tobacco smoking: a population-based study. BMC Public Health 14, 565.

Linscott RJ, van Os J (2013). An updated and conservative systematic review and meta-analysis of epidemiological evidence on psychotic experiences in children and adults: on the pathway from proneness to persistence to dimensional expression across mental disorders. Psychological Medicine 43, 1133-1149.

Lunn MR, Cui W, Zack MM, Thompson WW, Blank MB, Yehia BR (2017). Sociodemographic Characteristics and Health Outcomes Among Lesbian, Gay, and Bisexual U.S. Adults Using Healthy People 2020 Leading Health Indicators. LGBT Health 4, 283-294.

MacKinnon DP, Krull JL, Lockwood CM (2000). Equivalence of the Mediation, Confounding and Suppression Effect. Prevention science: the official journal of the Society for Prevention Research 1, 173.

McGrath JJ, Saha S, Al-Hamzawi A, Alonso J, Bromet EJ, Bruffaerts R, Caldas-de-Almeida JM, Chiu WT, de Jonge P, Fayyad J, Florescu S, Gureje O, Haro JM, Hu C, Kovess-Masfety V, Lepine JP, Lim CW, Mora MEM, Navarro-Mateu F, Ochoa S, Sampson N, Scott K, Viana MC, Kessler RC (2015). Psychotic experiences in the general population: a cross-national analysis based on 31,261 respondents from 18 countries. JAMA psychiatry 72 , $697-705$.

McManus S, Meltzer H, Brugha T, Bebbington P, Jenkins R (2009). Adult Psychiatric Morbidity in England, 2007: Results of a Household Survey. The NHS Information Centre for Health and Social Care: London. 
McNamara MC, $\mathbf{N g ~ H}$ (2016). Best practices in LGBT care: A guide for primary care physicians. Cleveland Clinic Journal of Medicine 83, 531-541.

Mollborn S, Everett B (2015). Understanding the Educational Attainment of Sexual Minority Women and Men*. Research in social stratification and mobility 41, 40-55.

Moreno C, Nuevo R, Chatterji S, Verdes E, Arango C, Ayuso-Mateos JL (2013). Psychotic symptoms are associated with physical health problems independently of a mental disorder diagnosis: results from the WHO World Health Survey. World Psychiatry 12, 251-257.

Niemantsverdriet MBA, Slotema CW, Blom JD, Franken IH, Hoek HW, Sommer IEC, Gaag M van der (2017). Hallucinations in borderline personality disorder: Prevalence, characteristics and associations with comorbid symptoms and disorders. Scientific Reports 7, 13920.

Oh H, Koyanagi A, Kelleher I, DeVylder J (2018). Psychotic experiences and disability: Findings from the Collaborative Psychiatric Epidemiology Surveys. Schizophrenia Research 193, 343-347.

Pakula B, Shoveller JA (2013). Sexual orientation and self-reported mood disorder diagnosis among Canadian adults. BMC Public Health 13, 209.

Reeve S, Emsley R, Sheaves B, Freeman D (2018). Disrupting Sleep: The Effects of Sleep Loss on Psychotic Experiences Tested in an Experimental Study With Mediation Analysis. Schizophrenia Bulletin 44, 662-671.

Reuter TR, Sharp C, Kalpakci AH, Choi HJ, Temple JR (2016). Sexual Orientation and Borderline Personality Disorder Features in a Community Sample of Adolescents. Journal of Personality Disorders 30, 694-707.

Roberts AL, Austin SB, Corliss HL, Vandermorris AK, Koenen KC (2010). 
Pervasive Trauma Exposure Among US Sexual Orientation Minority Adults and

Risk of Posttraumatic Stress Disorder. American Journal of Public Health 100, 2433-2441.

Sharifi V, Eaton WW, Wu LT, Roth KB, Burchett BM, Mojtabai R (2015).

Psychotic experiences and risk of death in the general population: 24-27 year follow-up of the Epidemiologic Catchment Area study. The British Journal of Psychiatry 207, 30-36.

Smyth N, Siriwardhana C, Hotopf M, Hatch SL (2015). Social networks, social support and psychiatric symptoms: social determinants and associations within a multicultural community population. Social Psychiatry and Psychiatric Epidemiology 50, 1111-1120.

Tien AY, Anthony JC (1990). Epidemiological analysis of alcohol and drug use as risk factors for psychotic experiences. The Journal of Nervous and Mental Disease 178, 473-480.

Tomaka J, Thompson S, Palacios R (2006). The Relation of Social Isolation, Loneliness, and Social Support to Disease Outcomes Among the Elderly. Journal of Aging and Health 18, 359-384.

Varghese D, Scott J, Welham J, Bor W, Najman J, O'Callaghan M, Williams G, McGrath J (2011). Psychotic-Like Experiences in Major Depression and Anxiety Disorders: A Population-Based Survey in Young Adults. Schizophrenia Bulletin 37, 389-393. 


\section{Tables and Figures}

Figure 1. Association between sexual orientation (exposure) and different types of psychotic experience or any psychotic experience (outcomes) estimated by multivariable logistic regression

Abbreviation: OR Odds ratio; $\mathrm{Cl}$ Confidence interval.

Participants were asked about their sexual orientation, and sexual orientation was dichotomized into heterosexual and non-heterosexual (i.e., mostly/mainly heterosexual, bisexual, mostly/mainly homosexual, entirely/completely homosexual, other).

Models were adjusted for sex, age and ethnicity.

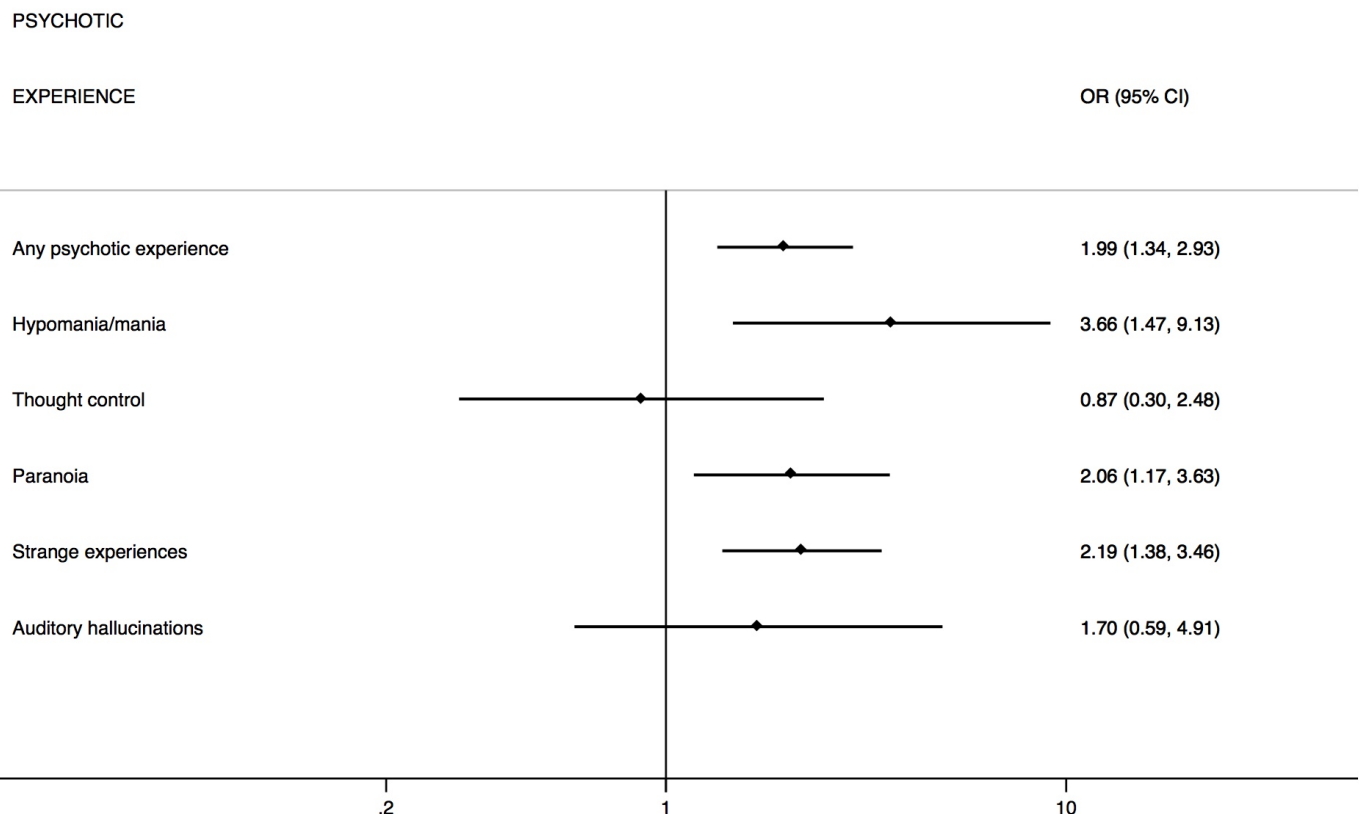


Table 1. Sample characteristics (overall and by sexual orientation)

\begin{tabular}{|c|c|c|c|c|c|}
\hline & & & Sexual orienta & & \\
\hline Characteristics & Category & Overall & Heterosexual & $\begin{array}{l}\text { Non- } \\
\text { heterosexual }\end{array}$ & $\begin{array}{l}\text { P- } \\
\text { value }^{a}\end{array}$ \\
\hline \multirow[b]{2}{*}{ Sex } & Male & 48.7 & 48.8 & 47.4 & \multirow[b]{2}{*}{0.582} \\
\hline & Female & 51.3 & 51.2 & 52.6 & \\
\hline Age (years) & Mean (SD) & \begin{tabular}{|l|}
46.3 \\
$(18.5)$
\end{tabular} & $46.7(18.5)$ & $40.7(17.7)$ & $<0.001$ \\
\hline \multirow{2}{*}{ British White } & No & 14.7 & 14.2 & 21.6 & \multirow{2}{*}{$<0.001$} \\
\hline & Yes & 85.3 & 85.8 & 78.4 & \\
\hline \multirow{2}{*}{ Marital status } & Single/widowed/divorced/separated & 36.9 & 35.7 & 53.8 & \multirow{2}{*}{$<0.001$} \\
\hline & Married/cohabiting & 63.1 & 64.3 & 46.2 & \\
\hline \multirow{2}{*}{ Qualification } & No & 23.7 & 23.8 & 22.4 & \multirow{2}{*}{0.504} \\
\hline & Yes & 76.3 & 76.2 & 77.6 & \\
\hline \multirow{2}{*}{ Employment } & No & 38.9 & 39.0 & 38.1 & \multirow{2}{*}{0.713} \\
\hline & Yes & 61.1 & 61.0 & 61.9 & \\
\hline \multirow{3}{*}{ Income } & Highest & 36.0 & 36.1 & 35.4 & \multirow{3}{*}{0.329} \\
\hline & Middle & 32.6 & 32.8 & 29.8 & \\
\hline & Lowest & 31.4 & 31.1 & 34.9 & \\
\hline \multirow{2}{*}{$\begin{array}{l}\text { Nicotine } \\
\text { dependence }\end{array}$} & No & 97.0 & 97.1 & 95.7 & \multirow{2}{*}{0.102} \\
\hline & Yes & 3.0 & 2.9 & 4.3 & \\
\hline \multirow{2}{*}{$\begin{array}{l}\text { Alcohol } \\
\text { dependence }\end{array}$} & No & 92.3 & 92.8 & 85.1 & \multirow{2}{*}{$<0.001$} \\
\hline & Yes & 7.7 & 7.2 & 14.9 & \\
\hline \multirow{2}{*}{ Cannabis use } & No & 92.5 & 93.2 & 83.9 & \multirow{2}{*}{$<0.001$} \\
\hline & Yes & 7.5 & 6.8 & 16.1 & \\
\hline \multirow{2}{*}{ Loneliness } & No & 79.8 & 80.8 & 67.5 & \multirow{2}{*}{$<0.001$} \\
\hline & Yes & 20.2 & 19.2 & 32.5 & \\
\hline Social support ${ }^{d}$ & Mean (SD) & $\begin{array}{l}13.2 \\
(1.9) \\
\end{array}$ & $13.2(1.8)$ & $12.7(2.4)$ & $<0.001$ \\
\hline \multirow{2}{*}{$\begin{array}{l}\text { Bullying } \\
\text { victimization }\end{array}$} & No & 79.7 & 80.7 & 66.1 & \multirow{2}{*}{$<0.001$} \\
\hline & Yes & 20.3 & 19.3 & 33.9 & \\
\hline \multirow{2}{*}{ Perceived stress } & No & 39.4 & 40.2 & 28.5 & \multirow{2}{*}{$<0.001$} \\
\hline & Yes & 60.6 & 59.8 & 71.5 & \\
\hline $\begin{array}{l}\text { Number of } \\
\text { stressful life } \\
\text { events }\end{array}$ & Mean (SD) & \begin{tabular}{|l|}
3.5 \\
$(2.4)$ \\
\end{tabular} & $3.4(2.4)$ & $3.9(2.9)$ & 0.001 \\
\hline \multirow{2}{*}{$\begin{array}{l}\text { Discrimination } \\
\text { due to sexual } \\
\text { orientation }\end{array}$} & No & 99.5 & 99.9 & 94.3 & \multirow{2}{*}{$<0.001$} \\
\hline & Yes & 0.5 & 0.1 & 5.7 & \\
\hline Common mental & No & 92.4 & 92.9 & 88.1 & $<0.001$ \\
\hline disorders & Yes & 7.6 & 7.1 & 14.0 & $<0.001$ \\
\hline Borderline & No & 96.3 & 97.0 & 88.1 & $<0001$ \\
\hline disorder traits & Yes & 3.7 & 3.0 & 11.9 & -0.001 \\
\hline Posttraumatic & No & 97.1 & 97.3 & 94.4 & $<0.001$ \\
\hline stress disorder & Yes & 2.9 & 2.7 & 5.6 & -0.001 \\
\hline Sleen nroblems & No & 57.9 & 58.6 & 48.3 & $<0001$ \\
\hline sleep probiems & Yes & 42.1 & 41.4 & 51.7 & $<0.001$ \\
\hline
\end{tabular}

Participants were asked about their sexual orientation, and sexual orientation was dichotomized into heterosexual and non-heterosexual (i.e., mostly/mainly heterosexual, bisexual, mostly/mainly homosexual, entirely/completely homosexual, other).

a $\mathrm{P}$-values were based on Chi-squared tests except for age, social support and the number of stressful life events (t-tests).

b Individuals who do not smoke were included in the category "no nicotine dependence".

"Individuals who do not consume alcohol were included in the category "no alcohol dependence".

d The variable on social support ranged from 0 to 14 , with higher scores representing higher levels of social support. 
Table 2. Mediating factors in the association between sexual orientation (independent variable) and any psychotic experience (dependent variable)

\begin{tabular}{|c|c|c|c|c|c|c|c|}
\hline & Total effect & & Direct effect & & Indirect effe & & \\
\hline Mediator & $\begin{array}{l}\text { OR } \\
{[95 \% \mathrm{Cl}]}\end{array}$ & $\begin{array}{l}\mathrm{P}- \\
\text { value }\end{array}$ & $\begin{array}{l}\text { OR } \\
{[95 \% \mathrm{Cl}]}\end{array}$ & $\begin{array}{l}\mathrm{P}- \\
\text { value }\end{array}$ & $\begin{array}{l}\text { OR } \\
{[95 \% \mathrm{Cl}]}\end{array}$ & $\begin{array}{l}\mathrm{P}- \\
\text { value }\end{array}$ & $\%$ Mediated \\
\hline Marital status & $\begin{array}{l}2.01 \\
{[1.38,2.93]}\end{array}$ & $<0.001$ & $\begin{array}{l}1.83 \\
{[1.25,2.69]}\end{array}$ & 0.002 & $\begin{array}{l}1.09 \\
{[1.05,1.15]}\end{array}$ & $<0.001$ & 13.0 \\
\hline Qualification & $\begin{array}{l}1.99 \\
{[1.37,2.90]}\end{array}$ & $<0.001$ & $\begin{array}{l}1.97 \\
{[1.35,2.86]}\end{array}$ & $<0.001$ & $\begin{array}{l}1.01 \\
{[1.00,1.03]}\end{array}$ & 0.158 & $N A^{a}$ \\
\hline Employment & $\begin{array}{l}1.99 \\
{[1.36,2.90]}\end{array}$ & $<0.001$ & $\begin{array}{l}1.95 \\
{[1.33,2.84]}\end{array}$ & 0.001 & $\begin{array}{l}1.02 \\
{[1.00,1.05]}\end{array}$ & 0.093 & $N A^{a}$ \\
\hline Income & $\begin{array}{l}1.88 \\
{[1.21,2.92]}\end{array}$ & 0.005 & $\begin{array}{l}1.83 \\
{[1.18,2.84]}\end{array}$ & 0.007 & $\begin{array}{l}1.03 \\
{[0.99,1.07]}\end{array}$ & 0.163 & $N A^{a}$ \\
\hline $\begin{array}{l}\text { Nicotine } \\
\text { dependence }\end{array}$ & $\begin{array}{l}1.96 \\
{[1.32,2.90]}\end{array}$ & 0.001 & $\begin{array}{l}1.94 \\
{[1.31,2.86]}\end{array}$ & 0.001 & $\begin{array}{l}1.01 \\
{[0.99,1.03]}\end{array}$ & 0.281 & $N A^{a}$ \\
\hline $\begin{array}{l}\text { Alcohol } \\
\text { dependence }\end{array}$ & $\begin{array}{l}1.96 \\
{[1.34,2.86]}\end{array}$ & $<0.001$ & $\begin{array}{l}1.88 \\
{[1.28,2.74]}\end{array}$ & 0.001 & $\begin{array}{l}1.04 \\
{[1.01,1.08]}\end{array}$ & 0.013 & 6.4 \\
\hline Cannabis use & $\begin{array}{l}1.96 \\
{[1.34,2.88]}\end{array}$ & 0.001 & $\begin{array}{l}1.85 \\
{[1.26,2.73]}\end{array}$ & 0.002 & $\begin{array}{l}1.06 \\
{[1.02,1.10]}\end{array}$ & 0.006 & 8.4 \\
\hline Loneliness & $\begin{array}{l}1.90 \\
{[1.29,2.81]}\end{array}$ & 0.001 & $\begin{array}{l}1.58 \\
{[1.07,2.33]}\end{array}$ & 0.022 & $\begin{array}{l}1.21 \\
{[1.12,1.30]}\end{array}$ & $<0.001$ & 29.1 \\
\hline Social support & $\begin{array}{l}1.96 \\
{[1.34,2.87]}\end{array}$ & 0.001 & $\begin{array}{l}1.83 \\
{[1.24,2.68]}\end{array}$ & 0.002 & $\begin{array}{l}1.07 \\
{[1.03,1.12]}\end{array}$ & $<0.001$ & 10.5 \\
\hline $\begin{array}{l}\text { Bullying } \\
\text { victimization }\end{array}$ & $\begin{array}{l}1.96 \\
{[1.35,2.86]}\end{array}$ & $<0.001$ & $\begin{array}{l}1.76 \\
{[1.21,2.57]}\end{array}$ & 0.003 & $\begin{array}{l}1.11 \\
{[1.06,1.17]}\end{array}$ & $<0.001$ & 15.9 \\
\hline Perceived stress & $\begin{array}{l}2.00 \\
{[1.38,2.92]}\end{array}$ & $<0.001$ & $\begin{array}{l}1.88 \\
{[1.29,2.74]}\end{array}$ & 0.001 & $\begin{array}{l}1.06 \\
{[1.02,1.11]}\end{array}$ & 0.005 & 8.9 \\
\hline $\begin{array}{l}\text { Stressful life } \\
\text { events }\end{array}$ & $\begin{array}{l}1.86 \\
{[1.27,2.73]}\end{array}$ & 0.001 & $\begin{array}{l}1.59 \\
{[1.08,2.33]}\end{array}$ & 0.018 & $\begin{array}{l}1.17 \\
{[1.08,1.26]}\end{array}$ & $<0.001$ & 25.4 \\
\hline $\begin{array}{l}\text { Discrimination } \\
\text { due to sexual } \\
\text { orientation }\end{array}$ & $\begin{array}{l}1.86 \\
{[1.26,2.73]}\end{array}$ & 0.002 & $\begin{array}{l}1.76 \\
{[1.18,2.61]}\end{array}$ & 0.005 & $\begin{array}{l}1.06 \\
{[1.00,1.12]}\end{array}$ & 0.069 & $N A^{a}$ \\
\hline $\begin{array}{l}\text { Common mental } \\
\text { disorders }\end{array}$ & $\begin{array}{l}1.89 \\
{[1.27,2.82]}\end{array}$ & 0.002 & $\begin{array}{l}1.68 \\
{[1.13,2.52]}\end{array}$ & 0.011 & $\begin{array}{l}1.12 \\
{[1.05,1.19]}\end{array}$ & $<0.001$ & 18.1 \\
\hline $\begin{array}{l}\text { Borderline } \\
\text { personality } \\
\text { disorder traits }\end{array}$ & $\begin{array}{l}1.60 \\
{[1.03,2.49]}\end{array}$ & 0.035 & $\begin{array}{l}1.37 \\
{[0.88,2.14]}\end{array}$ & 0.167 & $\begin{array}{l}1.17 \\
{[1.08,1.27]}\end{array}$ & $<0.001$ & 33.5 \\
\hline $\begin{array}{l}\text { Posttraumatic } \\
\text { stress disorder }\end{array}$ & $\begin{array}{l}1.92 \\
{[1.30,2.86]}\end{array}$ & 0.001 & $\begin{array}{l}1.82 \\
{[1.23,2.71]}\end{array}$ & 0.003 & $\begin{array}{l}1.06 \\
{[1.01,1.11]}\end{array}$ & 0.025 & 8.3 \\
\hline Sleep problems & $\begin{array}{l}2.03 \\
{[1.38,2.97]}\end{array}$ & $<0.001$ & $\begin{array}{l}1.77 \\
{[1.20,2.61]}\end{array}$ & 0.004 & $\begin{array}{l}1.14 \\
{[1.07,1.23]}\end{array}$ & $<0.001$ & 19.1 \\
\hline
\end{tabular}

Abbreviations: OR Odds ratio; Cl Confidence interval.

Participants were asked about their sexual orientation, and sexual orientation was dichotomized into heterosexual and non-heterosexual (i.e., mostly/mainly heterosexual, bisexual, mostly/mainly homosexual, entirely/completely homosexual, other).

Any psychotic experience referred to the presence of at least one of: hypomania/mania, thought control, paranoia, strange experiences, and auditory hallucinations.

Models are adjusted for sex, age and ethnicity.

a Mediated percentage was only calculated when the indirect effect was significant ( $p$-value<0.05). 